Speed cameras

\section{Speed cameras under attack in the United Kingdom}

\section{P Pilkington}

\section{The health community must defend effective injury prevention interventions}

$\nabla r$ his commentary examines the current campaign against speed cameras in the United Kingdom. It reveals how a health intervention, even when shown to be effective at reducing deaths and injuries, can be subject to sustained attacks from highly organised antihealth forces. It calls for concerted action among health professionals to respond to the increasingly vocal motorist lobby groups. Health professionals have a duty to defend effective interventions from unwarranted attacks. They should communicate with the general public about the role of such interventions in improving health and takes steps to ensure that vocal lobby groups do not threaten evidence based injury prevention initiatives.

\section{HEALTH, ROAD TRAFFIC COLLISIONS, AND THE ROLE OF SPEED}

Road traffic collisions are an important cause of death and disability both worldwide and in the United Kingdom. ${ }^{1}$ By 2020 road traffic collisions will have moved from ninth to third place in the world ranking of the burden of disease. ${ }^{2}$ And each year in Britain around 3500 people are killed and 330000 are injured on the roads. ${ }^{3}$ Research in the United Kingdom estimates that at least one third of collisions are speed related. ${ }^{4}$

Measures to reduce traffic speed are considered key to reducing casualties on the road. ${ }^{56}$ In the United Kingdom speed cameras are used to help reduce traffic speeds, traffic collisions, and casualties. ${ }^{7}$ A major expansion of speed cameras is underway, led at police force level by multiagency groups called Safety Camera Partnerships. ${ }^{7}$ The camera partnerships include representatives from the police, local authorities, and National Health Service (NHS). The partnerships are centrally financed, and can also use income generated from fines to increase the number of cameras in their local area. The government hopes that the safety camera initiative will help it achieve its road safety targets.

\section{EFFECTIVENESS OF SPEED CAMERAS}

Speed cameras are an effective means of reducing road traffic collisions and related deaths and injuries. Speed camera research in Norway, Australia, Canada, and New Zealand has demonstrated camera effectiveness. ${ }^{8-11}$ There is also evidence from the United Kingdom. A study in London showed that cameras reduced accidents by $9 \%$, casualties by $12 \%$, and fatalities by $71 \% .^{12}$ And over the first two years of the safety camera project cameras reduced casualties by $35 \%$ at camera sites across eight pilot areas. $^{13}$

RISE OF THE ANTICAMERA LOBBY Despite the overwhelming evidence that speed cameras are an effective injury prevention intervention, they are subject to sustained criticism in the United Kingdom. As the number of cameras nationwide has increased, so too have the number of tickets to speeding motorists. This is not surprising considering that observations of vehicle speeds showed that $69 \%$ of motorists exceeded the $30 \mathrm{mph}$ limit in free flowing traffic.

Media coverage has been intense. At least one national newspaper has a dedicated email address just for articles about speed cameras. The Association of British Drivers (ABD), a lobby group that claims to be the "voice of the driver" has been especially effective in its campaign against cameras. The organisation, whose membership numbers less than 1000, has appeared on television and is frequently quoted in the national press. Their reach is not surprising as they send out press releases to over 240 media organisations each week. ${ }^{14}$ The ABD also provides standard letters for people to write to their local newspaper to complain about cameras. ${ }^{15}$ The group's claim, that cameras are merely a revenue generating device that has little health benefit, is often echoed in the British media.

But the speed camera war has taken a more sinister turn. A group called MAD (Motorists Against Detection) claim to have vandalised and destroyed up to 600 speed cameras during recent years. ${ }^{16}$ Last August the group targeted 29 speed cameras in London in just one night. ${ }^{17}$ Remarkably, certain elements of the press have been supportive of this behaviour. ${ }^{16}$ The language and rhetoric of MAD and the ABD is the same: there is a rejection of speed cameras as a health intervention, and indeed of excessive traffic speed as an important health problem.

While widespread speeding among the general public may be the result of a wider apathy towards road safety, the minority radical groups are the product of a dominant car culture. They portray car drivers as victims at the hands of an over controlling state. In reality, their aim is to have the freedom to drive the way they wish, at a speed of their choosing. They reject population approaches to road safety, including speed cameras and traffic calming measures. Significantly the majority of the British public support speed cameras. ${ }^{13}$

The rise of such groups is not limited to the United Kingdom. Similar, related groups exist in Australia, United States, Canada, Germany, and other countries. ${ }^{15}$ They represent a real threat to tackling the global problem of road traffic injuries.

\section{RESPONSE TO THE ANTICAMERA LOBBY}

The main aim of a lobby group is to effect change. The government, being the instigator and financer of the safety camera initiative, has been the motoring groups' target in the United Kingdom. And the groups have had some success. In December 2001 the government announced that all cameras that were part of the safety camera initiative would have to be made highly visible (bright yellow), thereby giving drivers a chance to slow down. ${ }^{18}$ Mobile camera locations are now also reported on local radio stations and listed on the internet. This policy change was enacted despite there being no evidence about how increasing the visibility of cameras would impact on camera effectiveness. It appeared to be a response to the vocal motoring groups.

Another response is new strict criteria that cameras can only be located on roads with a history of road collisions, deaths, and injuries. Although heading off criticisms that cameras were only placed in areas where the opportunity to generate income was greatest, the decision has not pleased road safety groups 
like the Slower Speeds Initiative. They argue that cameras should be used to prevent deaths and injuries on all roads, regardless of accident history: why should people have to die before cameras can be used on a certain stretch of road? Excessive vehicle speed causes a range of problems in communities, including generating fear and dissuading people from walking and cycling. ${ }^{\circ}$ These effects are currently not taken into account when locating cameras.

There have been more positive responses to respond to criticism. Some camera partnerships are now offering sessions on the dangers of speeding for those drivers caught travelling just above the cut off limit to provide education as well as enforcement.

There is also a move to increase public awareness around the health benefits of speed cameras. A leaflet explains how cameras can save the NHS money by reducing admissions to hospital. ${ }^{19}$ The average costs of treating a road traffic victim is compared to costs for other common procedures, such as hip replacements.

\section{RECOMMENDATIONS FOR ACTION}

Last year the $B M J$ published a special issue on road traffic and health, entitled "War on the Roads". ${ }^{1}$ Propaganda is an important part of any war, and use of propaganda is certainly evident in the current war on speed cameras in the United Kingdom. Unfortunately, despite being armed with the evidence, the Safety Camera Partnerships are struggling in their battle with motoring lobby groups.

Although the partnerships have good systems in place for publicity, they need help to combat the highly organised antihealth forces of the motoring lobby. The camera debate in the media often ignores (or is ignorant) of the health benefits of speed cameras. Health professionals should support and promote speed cameras as an effective injury prevention intervention by:
- Responding to critical letters and articles in the written press by presenting the evidence of speed camera effectiveness.

- Advocating speed camera usage as an effective injury prevention intervention on local and national radio and television.

- Working closely with local Safety Camera Partnerships to stress the health benefits of cameras at local events and in the local media.

Combating the motoring lobby propaganda at all levels is key. The Department of Health, itself a member of the national Safety Camera Partnership Board, can play an important part in ensuring that the speed camera debate is firmly rooted in health. It should work closely and publicly with the Department for Transport in supporting speed camera usage.

\section{CONCLUSIONS}

This commentary reveals how an evidence based health intervention is coming under attack in the United Kingdom. Advocacy from health professionals needs to more than match the highly organised work of opposing lobby groups. The majority of the British public recognise that speeding is dangerous. But after decades of only minimal enforcement, the population has become complacent. Now, with the increase in cameras, there is the real chance that behaviour can be changed at the population level. The situation in this country is a test case for countering the increasing global threat that motoring lobby groups pose to road traffic injury prevention activities. The hostile views of groups like the $\mathrm{ABD}$ are not typical, and we should not allow their minority interests to wreck valuable health interventions.

Injury Prevention 2003;9:293-294

Correspondence to: Paul Pilkington, University of the West of England, Glenside Campus, Blackberry Hill, Stapleton, Bristol BS16 1DD, UK; paul.pilkington@uwe.ac.uk

\section{REFERENCES}

1 Roberts I. War on the roads - the public health community must intervene. BMJ editorial. BMJ 2002;224: $1107-9$.

2 World Health Organisation. Overview of the environment and health in Europe in the 1990s. Geneva: WHO, 1999.

3 Department for Transport. Road accidents Great Britain 2001-the casualty report. London: Department for Transport, 2002.

4 Carsten OMJ, Tight MR, Southwell MT, et al. Urban accidents: why do they happen? Basingstoke: AA Foundation for Road Safety Research UK, 1989.

5 Department for Transport. New directions in speed management. A review of policy. London: The Stationery Office, 2000.

6 House of Commons Transport, Local Government and the Regions Committee. Road traffic speed. Ninth report of session 2001-2002, volume 1. London: House of Commons.

7 Department for the Environment, Transport and the Regions. Speed camera roll out. DETR press release. London: DETR, August, 2001.

8 Bourne M, Cooke R. Victoria's speed camera program. In: Clarke RV, ed. Crime prevention studies. New York: Criminal Justice Press, 1993; 1:177-92

9 Chen G, Wilson J, Meckle W, et al. Evaluation of photo radar program in British Colombia. Accid Anal Prev 2000;32:517-26.

10 Mara MK, Davies RB, Frith WJ. Evaluation of the effects of compulsory breath testing and speed cameras in New Zealand. Proceedings of the Australian Road Research Board 1996; 18:269-82.

11 Elvik $E$. Effects of accidents of automatic speed enforcement in Norway. Transportation Research Record 1997; 1597:14-19.

12 Highways Agency. West London Speed Camera Demonstration Project: analysis of accident data 36 months before and after implementation. London: London Accident Analysis Unit, 1997.

13 PA Consulting. A cost recovery system for speed and red light cameras - two year pilot evaluation. London: Department for Transport, 2003.

14 Association of British Drivers. On the road. The journal of the Association of British Drivers, issue $41,2000$.

15 Association of British Drivers website. Available at: http://www.abd.org.uk/ (last accessed on 23 June 2003).

16 Chancellor A. In need of speed. Guardian 2003. Available at: www.guardian.co.uk/Columnists/ Column/0,5673,971131,00.html (last accessed on 23 June. 2003).

17 Williams D. Vigilantes target cameras. This is London. Evening Standard. Available at: www.thisislondon.com/traffic/articles/ 2896095 ? source $=$ Evening\%20Standard (last accessed on 23 June 2003).

18 Department of the Environment, Transport and the Regions. Spellar announces new camera visibility rules. DETR news release 517 . London: DETR, 2001

19 National Safety Camera Liaison Office. Saving more than lives. UK: National Safety Camera Partnership, 2003. 